University of Nebraska - Lincoln

DigitalCommons@University of Nebraska - Lincoln

Papers in the Earth and Atmospheric Sciences

Earth and Atmospheric Sciences, Department

\title{
Metastable equilibria among dicarboxylic acids and the oxidation state during aqueous alteration on the $\mathrm{CM} 2$ chondrite parent body
}

Jason A. McAlister

University of Nebraska-Lincoln

Richard M. Kettler

University of Nebraska-Lincoln, rkettler1@unl.edu

Follow this and additional works at: https://digitalcommons.unl.edu/geosciencefacpub

Part of the Earth Sciences Commons

McAlister, Jason A. and Kettler, Richard M., "Metastable equilibria among dicarboxylic acids and the oxidation state during aqueous alteration on the CM2 chondrite parent body" (2007). Papers in the Earth and Atmospheric Sciences. 163.

https://digitalcommons.unl.edu/geosciencefacpub/163

This Article is brought to you for free and open access by the Earth and Atmospheric Sciences, Department of at DigitalCommons@University of Nebraska - Lincoln. It has been accepted for inclusion in Papers in the Earth and Atmospheric Sciences by an authorized administrator of DigitalCommons@University of Nebraska - Lincoln. 


\title{
Metastable equilibria among dicarboxylic acids and the oxidation state during aqueous alteration on the CM2 chondrite parent body
}

\author{
Jason A. McAlister and Richard M. Kettler \\ Department of Geosciences, University of Nebraska-Lincoln, Lincoln, NE 68588, USA \\ Corresponding author - R. M. Kettler, fax 402 472-4917, email rkettler2@unl.edu
}

\begin{abstract}
Linear saturated dicarboxylic acids are present in carbonaceous chondrite samples at concentrations that suggest aqueous alteration under conditions of metastable equilibrium. In this study, previously published values of dicarboxylic acid concentrations measured in Murchison, Yamato-791198, and Tagish Lake carbonaceous chondrites are converted to aqueous activities during aqueous alteration assuming water:rock ratios that range from 1:10 to 10:1. Logarithmic plots of the aqueous activities of any two dicarboxylic acids are proximal to lines whose slope is fixed by the stoichiometry of reactions describing the oxidation-reduction equilibrium between the two species. The precise position of any line is controlled by the equilibrium constant of the reaction relating the species and the hydrogen fugacity for the reaction of interest. Reactions among succinic (C4), glutaric (C5), and adipic (C6) acids obtained from CM2 chondrites show evidence of metastable equilibrium and yield $\log f_{\mathrm{H}_{2}}$ values that agree to within $0.3 \log$ units at $298.15 \mathrm{~K}$ and $0.6 \log$ units at $473.15 \mathrm{~K}$. At a water:rock ratio of 1:1, metastable equilibrium among succinic, glutaric, and adipic acids results in calculated $\log f_{\mathrm{H}_{2}}$ values during aqueous alteration that range from -6.2 at $298.15 \mathrm{~K}$ to -3.3 at $373.15 \mathrm{~K}$. These values are consistent with those obtained in previous work on carbonaceous chondrites and with metastable equilibrium at temperatures ranging from 300 to $355 \mathrm{~K}$ in contact with cronstedtite + magnetite.
\end{abstract}

\section{Introduction}

Carbonaceous chondrites represent a subset of meteorites from which an abundant suite of organic compounds have been extracted (reviewed by Botta and Bada, 2002; Sephton, 2002; Pizzarello et al., 2006). There is considerable interest in the origin of the reduced carbon species present in these meteorites: these species represent a potential initial stock of organic compounds for the early Earth (Chyba and Sagan, 1992). The carbonaceous chondrites are derived from multiple asteroidal parent bodies that underwent post-accretional aqueous alteration (Barber, 1985; Kerridge, 1991; Krot et al., 2003). Although the timing and mechanism of organic synthesis remains unknown, one possibility is that organic synthesis was coincident with all or part of the aqueous alteration (Kerridge and Bunch, 1979; Barber, 1985; Cronin et al., 1993). Schulte and Shock (2004) have tested that hypothesis by simulating organic synthesis under conditions of metastable equilibrium during meteorite alteration. Their work indicates that synthesis of classes of hydrophilic organic species during aqueous alteration was possible. It is appropriate therefore to consider whether evidence of alteration of organic species or organic synthesis is preserved in the abundances of individual species within these compound classes.

The dicarboxylic acids are a particularly apposite choice for this examination. They are simple chemically, consisting only of carbon, hydrogen, and oxygen arranged in simple functional groups, whereas other organic compounds found in meteorites have more complex elemental or struc- 
tural chemistry. The presence of a carboxylic acid functional group on each end of the molecule suggests that the terminal carbon atom experienced electron transfer: a freeradical termination reaction involving two carboxylic acid radical species in a dilute aqueous solution is unlikely.

The synthesis of organic compounds found in carbonaceous chondrites is an area of debate and continued research; "given the large compositional and isotopic differences (among the organic compounds identified in carbonaceous chondrites) an inclusive theory for the origin of all the varied organic constituents in carbonaceous chondrites appears hard to formulate" (Pizzarello et al., 2006). Organic compounds isolated from carbonaceous chondrites exhibit large $\mathrm{D} / \mathrm{H}$ ratios and positive $\delta^{13} \mathrm{C}$ values, indicating that the first organic molecules, or at least the reactants leading to their production via proposed FisherTropsch type (FTT) (Anders et al., 1973) or Strecker (Peltzer et al., 1984) synthesis pathways, were the products of low temperature ion reactions in an interstellar environment (Cronin et al., 1993; Pizzarello and Huang, 2002). These molecules were analogous to the anhydrous inorganic mineral species that existed on the parent body before alteration. Irrespective of the mechanism of synthesis, organic compounds were present on the parent body and hydrophilic species occurred as solutes in the aqueous solution during the alteration event (Brearley, 2006; Krot et al., 2006). Additional hydrophilic organic molecules may have been synthesized from oxidized forms of carbon during aqueous alteration whereas others were formed from prexisting hydrophobic or hydrophilic organic species. The suite of resulting compounds is a product of pre-accretionary synthesis and the aqueous alteration event. The chemistry of the latter event, and perhaps the distribution of the hydrophilic organic species, was controlled partly by the $f_{\mathrm{H}_{2}}$ environment imparted by the mineral assemblage.

This work attempts to test the evidence for metastable equilibrium among dicarboxylic acids extracted from carbonaceous chondrites. Stable thermodynamic equilibrium predicts that carbon containing compounds will exist either in the oxidized form of $\mathrm{CO}_{2}$ or the reduced forms of $\mathrm{CH}_{4}$, graphite, or diamond. The abiotic synthesis and preservation of organic compounds in carbonaceous chondrites would not be expected based on stable thermodynamic equilibrium. Minimizing chemical potential requires favorable reaction kinetics: the reaction products favored thermodynamically will only be obtained provided there is a minimal activation energy to allow the reaction to occur. It is, however, possible for some systems to achieve metastable equilibrium. Reactions at metastable equilibrium are reversible and the relative abundance of species in the reaction of interest are fixed by the equilibrium constant of the reaction. Metastable equilibrium has been documented for reactions between ethane and ethene (Seewald, 1994) and for the interconversion of formic acid to carbon dioxide (McCollom and Seewald, 2003). There is evidence that acetic acid and propanoic acid, and propanoic acid and butanoic acid are in metastable equilibrium in sedimentary basins (Shock, 1988, 1989, 1990; Helgeson et al., 1993). Thus the possibility that speciation of dicarboxylic acids during aqueous alteration on asteroids was controlled by conditions of metastable equilibrium is an intriguing one. If evidence of metastable equilibrium among the dicarboxylic acid species can be obtained, then the oxidation state of the aqueous alteration event during which the dicarboxylic acids equilibrated can be retrieved. The calculated oxidation state would allow estimates of the oxidation state of the fluid during aqueous alteration of the parent body to be constrained.

\section{Methods}

Five studies of dicarboxylic acids in carbonaceous chondrites were reviewed from literature (Table 1). Dicarboxylic acid concentrations have been measured in (1) Murchison (CM2) and (2) Yamato-791198 (CM2) meteorites (Shimoyama and Shigematsu, 1994) following extraction with water at 298 K (A. Shimoyama, private communication, 2006). High-temperature extraction of dicarboxylic acids was performed for the (3) Tagish Lake (Unclassified, exhibiting CM to CI characteristics; Zolensky et al., 2002) meteorite (extraction in water for $24 \mathrm{~h}$ at 383 K) (Pizzarello and Huang, 2002), (4) Murchison meteorite (extraction in water for $20 \mathrm{~h}$ at $373 \mathrm{~K}$ ) (Peltzer, 1979), and (5) Murchison meteorite (extraction in water for $24 \mathrm{~h}$ at $373 \mathrm{~K}$ ) (Martins et al., 2006).

Assessment of metastable equilibria based on the relative concentrations of organic acids follows the methods of Shock $(1988,1989)$. The slopes of log activity plots of organic acids involved in redox reactions are shown to correspond to those predicted by the linear rearrangement of the mass action equation governing the reaction of interest. Use of this method requires the calculation of the activities of dicarboxylic acids present during aqueous alteration on the asteroid. Measured concentrations (nmol/g meteorite) (Table 1) were converted to molal concentrations (mol/ $\mathrm{kg}$ solvent) at water:rock mass ratios of 1:10, 1:1 and 10:1 and then to aqueous activities (Table 1) by assuming unit activity coefficients $(\gamma)$. These water:rock ratios bracket those proposed for CM chondrite alteration (Clayton and Mayeda, 1999) and are consistent with models of organic synthesis during aqueous alteration on asteroids that have utilized water:rock ratios of 1:1 to 10:1 by mass (Schulte and Shock, 2004).

Consideration of solubility data (Seidell, 1941; Apelblat and Manzurola, 1987) suggests that the concentrations of dicarboxylic acids measured in carbonaceous chondrites are sufficiently low that these species would have been undersaturated during aqueous alteration on the asteroid and during extraction. Reactions among linear saturated dicarboxylic acids have the form:

$$
\begin{aligned}
X \mathrm{C}_{Y} \mathrm{H}_{(2 Y-2)} \mathrm{O}_{4}+5(X-Y) \mathrm{H}_{2} \rightleftarrows Y \mathrm{C}_{X} \mathrm{H}_{(2 X-2)} \mathrm{O}_{4} \\
+4(X-Y) \mathrm{H}_{2} \mathrm{O}
\end{aligned}
$$

where $X$ and $Y$ are stoichiometric reaction coefficients fixed by the selection of the species of interest. Linear rearrangement of the mass action equation yields:

$$
\begin{aligned}
\log \boldsymbol{a}_{\mathrm{CYH}(2 Y-2) \mathrm{O} 4}= & (Y / X) \log a_{\mathrm{CXH}(2 X-2) \mathrm{O} 4} \\
& -(1 / X)\left[5(X-Y) \log f_{\mathrm{H}_{2}}+\log K_{\mathrm{r}}\right]
\end{aligned}
$$




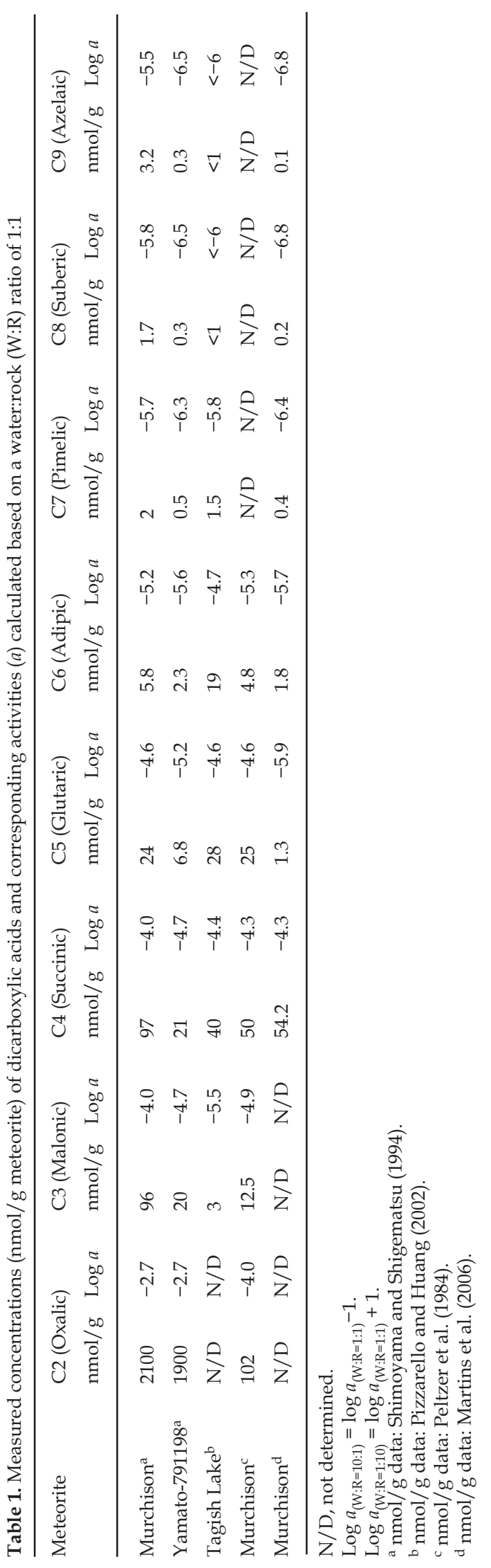

where $a$ represents the activity of the subscripted species, $f$ is the fugacity, and $K_{\mathrm{r}}$ is the equilibrium constant for the reaction in Equation (1). This rearrangement yields the equation for a straight line in $\log a_{\mathrm{CYH}(2 Y-2) \mathrm{O}_{4}}$ vs. $\log a_{\mathrm{CXH}_{(2 X-2)} \mathrm{O}_{4}}$ space. If two dicarboxylic acids are in metastable equilibrium, then a plot of the logarithm of the activities of these two species will yield a straight line with a slope $(Y / X)$ fixed by the stoichiometry of the reaction and an intercept $(b)$

$$
b=-(1 / X)\left[\left(5(X-\gamma) \log f_{\mathrm{H}_{2}}+\log K_{\mathrm{r}}\right.\right.
$$

fixed by the equilibrium constant $\left(K_{\mathrm{r}}\right)$, the reaction stoichiometry, and the oxidation state $\left(\log f_{\mathrm{H}_{2}}\right)$.

The value of $\log f_{\mathrm{H}_{2}}$ is calculated from the intercept by rearranging Equation (3):

$$
\log f_{\mathrm{H}_{2}}=\left(-b X-\log K_{\mathrm{r}}\right) /[5(X-Y)]
$$

Because the slope of the line that corresponds to Equation (2) is fixed by the reaction stoichiometry it is inappropriate to generate the slope and intercept by a conventional least squares analysis. The $\log a_{\mathrm{CYH}(2 Y-2) \mathrm{O}_{4}}$-intercept was therefore calculated by minimizing the variance $\left(s^{2}\right)$ which is calculated according to Equation (5)

$$
s^{2}=\sum\left(y_{i}-y_{\text {calculated }}\right)^{2}
$$

$y_{i}$ is the observed value of the $\log a_{C \gamma \mathrm{H}(2 Y-2) \mathrm{O}_{4}}$ and $y_{\text {calculated }}$ is the value of $\log a_{\mathrm{CYH}(2 Y-2) \mathrm{O}_{4}}$ given the requisite slope and the calculated intercept. The intercept is then calculated from

$$
b=\left[\sum y_{i}-(Y / X) \cdot \sum x_{i}\right] / N
$$

where $x_{\mathrm{i}}$ is the value of $\log a_{\mathrm{CXH}(2 \mathrm{X}-2) \mathrm{O}_{4}}$ and $N$ is the number of observations. Because the value of the variance is dependent on $N$, division by $N$ allows the variance to be normalized and data sets of different sample sizes to be compared.

Note that in minimizing the variance, the slope of the lines does not indicate a best fit to the data; rather the resulting line indicates log activity values predicted by metastable equilibrium between two compounds. The proximity of the data to this line is indicated by the variance, allowing for quantitative comparison among data sets. While the selection of the water:rock ratio will not affect the slope of the activity plots, it will affect the value of the $\log a_{\mathrm{CYH}(2 Y-2) \mathrm{O}_{4}}$-intercept. To assess the sensitivity of this factor, calculations were made with water:rock ratios of $10: 1,1: 1$, and $1: 10$ by mass.

Calculation of the $\log a_{\mathrm{CYH}(2 Y-2) \mathrm{O} 4}$-intercept allows the fugacity $(f)$ of $\mathrm{H}_{2}$ at a given temperature (Equation (3)) to be retrieved provided the equilibrium constant is known. Equilibrium constants for the reactions of interest $\left(K_{\mathrm{r}}\right)$ (Table 2) were obtained from the change in standard Gibbs energy for the reaction

$$
\log K_{\mathrm{r}}=-\Delta_{\mathrm{r}} G^{\circ} /(2.303 R T) \text {. }
$$

Values of the standard Gibbs energy of formation $\left(\Delta_{\mathrm{f}} \mathrm{G}^{\circ}\right)$ for each acid of interest were calculated via a functional group contribution model (Yezdimer et al., 2000) at the saturation pressure of water. The functional group additivity model of Yezdimer et al. (2000) assigns an equal contribution to a "hydrocarbon" carbon atoms irrespective of whether the carbon atom is a primary, secondary, or tertiary carbon. 
Table 2. Equilibrium constants for reactions between succinic, glutaric, and adipic acids at $295.15-473.15 \mathrm{~K}$ at the saturation pressure of water

\begin{tabular}{lcccccc}
\hline$T(\mathrm{~K})$ & \multicolumn{1}{l}{$\log K_{\mathrm{r}}$} & \multicolumn{1}{c}{$\mathrm{C}$} \\
\cline { 2 - 7 } & $\mathrm{A}$ & $\mathrm{B}$ & $\mathrm{C}$ & $\mathrm{D}$ & $\mathrm{E}$ & $\mathrm{F}$ \\
\hline 298.15 & 33.0 & 66.0 & -33.0 & 33.1 & -66.0 & -33.1 \\
348.15 & 22.8 & 45.3 & -22.8 & 22.4 & -45.3 & -22.4 \\
373.15 & 18.8 & 37.2 & -18.8 & 18.3 & -37.2 & -18.3 \\
423.15 & 12.5 & 24.3 & -12.5 & 11.7 & -24.3 & -11.7 \\
473.15 & 7.5 & 14.3 & -7.5 & 6.5 & -14.3 & -6.5 \\
\hline
\end{tabular}

Reactions:

(A) $5 \mathrm{C}_{4} \mathrm{H}_{6} \mathrm{O}_{4}+5 \mathrm{H}_{2}=4 \mathrm{C}_{5} \mathrm{H}_{8} \mathrm{O}_{4}+4 \mathrm{H}_{2} \mathrm{O}$;

(B) $6 \mathrm{C}_{4} \mathrm{H}_{6} \mathrm{O}_{4}+10 \mathrm{H}_{2}=4 \mathrm{C}_{6} \mathrm{H}_{10} \mathrm{O}_{4}+8 \mathrm{H}_{2} \mathrm{O}$;

(C) $4 \mathrm{C}_{5} \mathrm{H}_{8} \mathrm{O}_{4}+4 \mathrm{H}_{2} \mathrm{O}=5 \mathrm{C}_{4} \mathrm{H}_{6} \mathrm{O}_{4}+5 \mathrm{H}_{2}$;

(D) $6 \mathrm{C}_{5} \mathrm{H}_{8} \mathrm{O}_{4}+5 \mathrm{H}_{2}=5 \mathrm{C}_{6} \mathrm{H}_{10} \mathrm{O}_{4}+4 \mathrm{H}_{2} \mathrm{O}$;

(E) $4 \mathrm{C}_{6} \mathrm{H}_{10} \mathrm{O}_{4}+8 \mathrm{H}_{2} \mathrm{O}=6 \mathrm{C}_{4} \mathrm{H}_{6} \mathrm{O}_{4}+10 \mathrm{H}_{2}$;

(F) $5 \mathrm{C}_{6} \mathrm{H}_{10} \mathrm{O}_{4}+4 \mathrm{H}_{2} \mathrm{O}=6 \mathrm{C}_{5} \mathrm{H}_{8} \mathrm{O}_{4}+5 \mathrm{H}_{2}$.

Although this approach yields a model that can be applied to a wide variety of organic compounds, it also results in the calculation of identical values for thermodynamic properties of isomeric compounds. Calculation of $\Delta_{\mathrm{f}} \mathrm{G}^{\circ}$ for isomeric compounds using the Yezdimer et al. (2000) model is, therefore, dependent on accurate experimental values of the enthalpy $\left(\Delta_{\text {hyd }} H^{\circ}\right)$ and entropy of hydration $\left(\Delta_{\text {hyd }} S^{\circ}\right)$ of the compound of interest at $298.15 \mathrm{~K}$. These values are not available, however, for many branched dicarboxylic isomers of linear dicarboxylic acids.

Thermodynamic calculations for inorganic species were made using The Geochemist's Workbench v. 5.0.2 and the thermo.com.v8.r6+.dat database.

\section{Results}

The plots in Figure 1 are used to evaluate the evidence that the C4-C9 linear saturated dicarboxylic acids were in metastable equilibrium during aqueous alteration on the parent body. The fill patterns of the symbols in Figure 1 represent the individual dicarboxylic acids in this study. The shapes of the symbols in Figure 1 represent the carbonaceous chondrite from which the acid was extracted. To prevent congestion on the plots, an offset $(Z)$ is incorporated wherein the values for the log activities of suberic (C8) and azelaic (C9) acids are decreased by 0.5 and $1.0 \log$ units, respectively. No offset is required for the other acids and thus $Z=0$ for these species. Each line is labeled with the normalized variance $\left(s^{2} / N\right)$ associated with the data points obtained from the CM2 chondrites (Figure 1).

All known measurements of dicarboxylic acids were included in Table 1. The results from the Tagish Lake samples are generally similar to those obtained from the CM2 chondrite samples (Table 1 and Figure 1). It has been suggested that $\mathrm{CM}$ and $\mathrm{CI}$ carbonaceous chondrites originated from progressive alteration of similar parent body assemblages (Zolensky et al., 1989) and that stones classified as $\mathrm{CM}$ and $\mathrm{CI}$, as well as Tagish Lake, may have originated from the same parent body (Brandon et al., 2005). Whereas the $\Delta^{17} \mathrm{O}$ values of carbonates and structural and interlayer water from the Murchison meteorite are negative, the corresponding values from the Tagish Lake meteorite

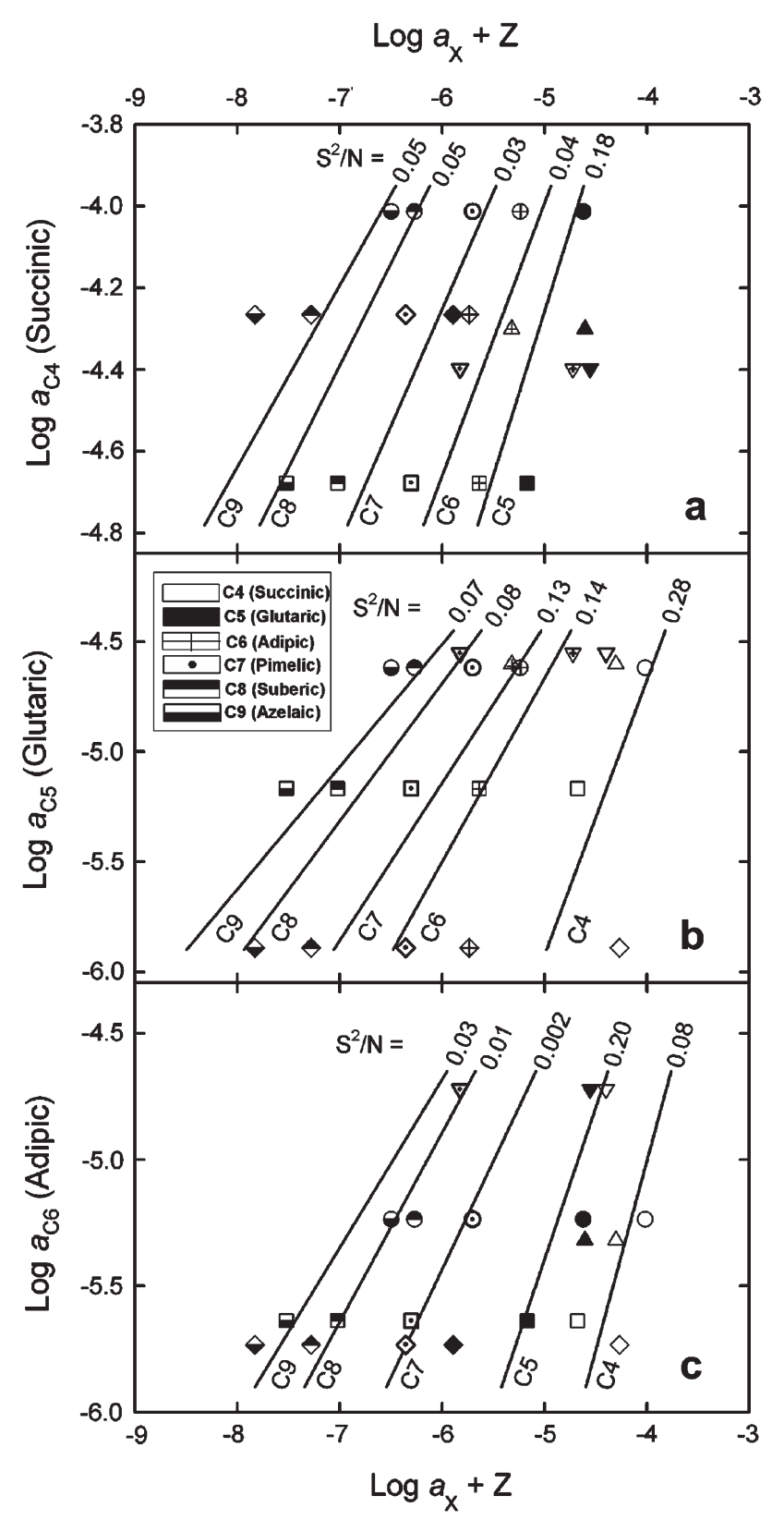

Figure 1. Plots of (a) $\log a_{\mathrm{C} 4 \text { (Succinic) }}$ (b) $\log a_{\mathrm{C} 5 \text { (Adipic)' }}$ (c) $\log a_{\mathrm{C} 6 \text { (Glu- }}$ taric) versus log a linear saturated dicarboxylic acids of 4-9 carbon atoms reveal trends along lines of slope indicating metastable equilibrium among the acids. The normalized variance is indicated in bold above each line. The shape of the plot indicates data source: (o) Murchison (Shimoyama and Shigematsu, 1994), () Yamato-791198 (Shimoyama and Shigematsu, 1994), ( $\nabla)$ Tagish Lake (Pizzarello and Huang, 2002), ( $\Delta$ ) Murchison (Peltzer et al., 1984), ( $\diamond)$ Murchison (Martins et al., 2006). For suberic (C8) and azelaic (C9) acids $Z$ equals -0.50 and -1.0 , respectively; $Z$ equals zero for all other acids. The plots represent activities calculated based on a water:rock ratio of 1:1. The slope of the lines and the calculated variance is independent of the water:rock ratio.

are positive (Baker et al., 2002). Thus alteration of the CM2 chondrites and the Tagish Lake meteorite occurred in sufficiently different environments that dicarboxylic acids from those meteorites could not have been in metastable equilibrium even if the objects were derived from the same parent body. Moreover, removal of the Tagish Lake samples does 
improve the fit of the data. If the Tagish Lake samples are removed the values of $s^{2} / N$ decrease for seven of the nine possible permutations (Figure 2). The Tagish Lake samples have been plotted in Figure 1 for reference only and have not been used in calculating the positions of the lines or the values of the normalized variance $\left(s^{2} / N\right)$ that are presented in Figure 1.

The slopes of the lines in Figure 1(a) are 4/5, 4/6, 4/7, 4/8, and 4/9 for the lines labeled C5, C6, C7, C8, and C9, respectively. Although the slopes are fixed, the position of each line is variable and is set by the intercept. The slopes predicted by Equation (2) are, however, relevant to the fitting of the plots. For example, in Figure 1c, the plots of $\log a_{\text {Adipic (C6) }}$ versus $\log a_{\text {Azelaic (C9) }}$ fit well $\left(s^{2} / N=0.03\right)$ to the slope of $6 / 9$ as required by the reaction stoichiometry. Use of another value for the slope would provide a poorer fit. For example, use of a slope of $6 / 4$ for these same data would yield a normalized variance with a much higher value $\left(s^{2} / N=0.41\right)$. The values of normalized variance obtained for the CM2 chondrite samples (Figure 1) compare favorably to normalized variance values of $\sim 0.02$ to 0.05 (calculated using data from Carothers and Kharaka, 1978; Willey et al., 1975) for the plots used by Shock (Shock, 1988, Figure 5; Shock, 1990, Figures 2-4) to demonstrate metastable equilibrium within oil field waters and sedimentary basins.

The reported concentrations of oxalic (C2) and malonic (C3) acids range widely among the four samples (Table 1). Malonic acid decarboxylates at low temperatures relative to other dicarboxylic acids; with a half life of approximately $3.5 \mathrm{~h}$ at $373 \mathrm{~K}$ (Maiella and Brill, 1996). Significant amounts of malonic acid would have decarboxylated during extraction of Murchison at $373 \mathrm{~K}$ for $20 \mathrm{~h}$ (Peltzer, 1979) and extraction of Tagish Lake at $383 \mathrm{~K}$ for $24 \mathrm{~h}$ (Pizzarello and Huang, 2002). The reason for the inconsistencies in reported oxalic acid concentrations is not readily apparent; non-catalytic decarboxylation of oxalic acid is minor over the extraction time intervals (Weber, 2004).

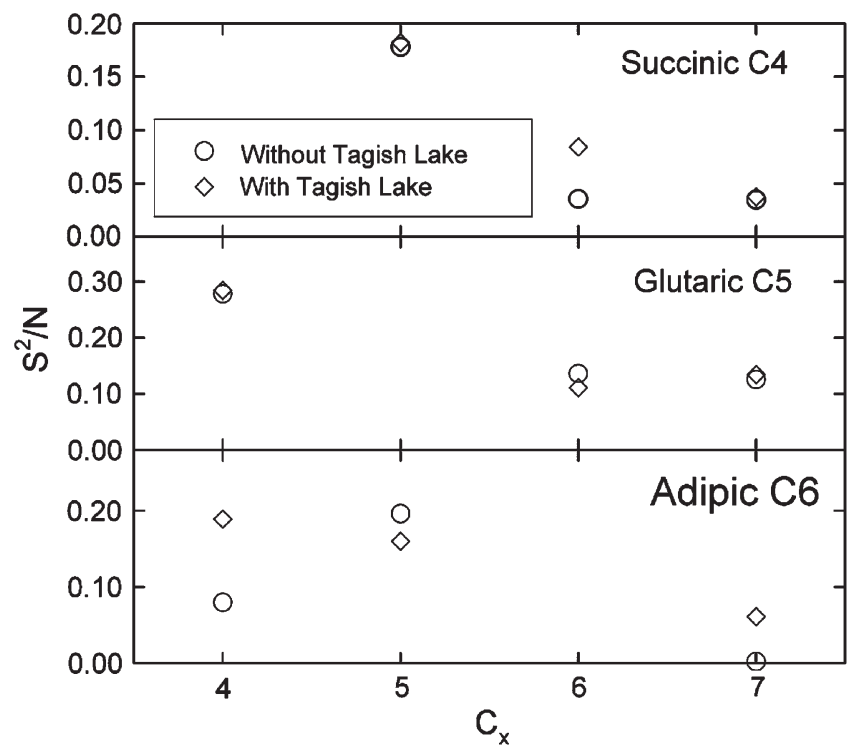

Figure 2. Plots of the normalized variance for fits both including and excluding results from the Tagish Lake meteorite.
Variations in dicarboxylic acid concentrations among Murchison samples may be a function of sample heterogeneity, extraction, and/or analysis techniques. Note that relevance lies in the ratios among dicarboxylic acids extracted from a sample, as opposed to absolute concentrations. The concentrations of dicarboxylic acids measured in the Murchison meteorite by Martins et al. (2006) are lower than those measured by Shimoyama and Shigematsu (1994) and Peltzer et al. (1984), particularly for glutaric (C5) and adipic (C6) acids. For example, the ratios of succinic:glutaric acid are 4.0, 2.0, and 42.1 as measured by Shimoyama and Shigematsu (1994), Peltzer et al. (1984), and Martins et al. (2006), respectively, and the ratios of succinic:adipic acid reported by the same workers are 16.7, 10.4, and 29.3. An earlier version of this publication was completed prior to the publication of Martins et al. (2006). Their data have subsequently been included in this version. Although inclusion of the Martins et al. data increases the scatter in the plots presented in Figure 1, the overall results and conclusions remain unchanged.

If the data for the C4 through C9 acids obtained from the $\mathrm{CM} 2$ chondrites do reflect metastable equilibrium, the oxidation state of the equilibration (Figure 3) may be calculated based on the $\log a_{\mathrm{CYH}(2 Y-2) \mathrm{O} 4}$-intercepts. Intercept values (Table 3 ) and equilibrium constants (Table 2) for the $\mathrm{C} 4$ through $\mathrm{C} 6$ acids were selected because these compounds were present in all four of the studies that examined CM2 chondrites. Although only three reactions are used to calculate the intercept values, each reaction is considered

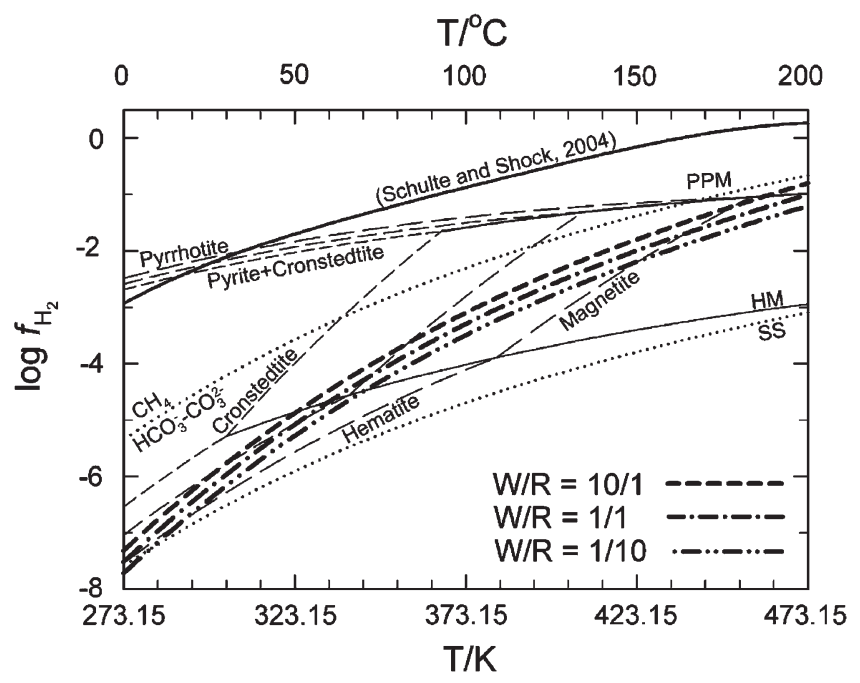

Figure 3. Calculation of $\log f_{\mathrm{H}_{2}}$ in this work at water:rock ratios of $1: 1$ (dash-dot line), 10:1 (dotted line), and 1:10 (dash-dot-dot) based on the $y$-intercept of graphs indicating metastable equilibrium between succinic, glutaric, and adipic acids at 298.15-473.15 K. The HematiteMagnetite (HM) and Pyrite-Pyrrhotite-Magnetite (PPM) buffers are shown extending from the right side of the diagram to the dashed line on the left side. The dashed lines define the cronstedtite stability field when $\log a \mathrm{SiO}_{2}$ is equal to quartz saturation minus $0.5 \log$ units (short dashed line), quartz saturation (medium dashed line), and quartz saturation plus $0.5 \mathrm{log}$ units (long dashed line). The short dashed lines designate the $\mathrm{CH}_{4(\mathrm{aq})}-\mathrm{HCO}_{3}^{-}$(aq) $-\mathrm{CO}_{3}^{2-}$ (aq) and $\mathrm{H}_{2} \mathrm{~S}_{(\mathrm{aq})}-\mathrm{SO}_{4}^{2-}(\mathrm{aq})-$ $\mathrm{HS}^{-}{ }_{\text {(aq) }}$ triple points. Also shown is the $\log f_{\mathrm{H}_{2}}-\mathrm{T}$ path generated during the coupled mineral alteration/organic synthesis simulation by Schulte and Shock (2004). 
Table 3. Intercept values calculated by minimizing variance of log activity plots for slopes fixed by reaction stoichiometry

\begin{tabular}{lllllll}
\hline Water/rock & \multicolumn{2}{l}{ Reaction } & & & & \\
\cline { 2 - 7 } & $\mathrm{A}$ & $\mathrm{B}$ & $\mathrm{C}$ & $\mathrm{D}$ & $\mathrm{E}$ & $\mathrm{F}$ \\
\hline $1 / 1$ & -0.26 & -0.66 & 0.32 & -0.50 & 0.99 & 0.60 \\
$10 / 1$ & -0.46 & -0.99 & 0.57 & -0.67 & 1.49 & 0.80 \\
$1 / 10$ & -0.06 & -0.33 & 0.07 & -0.34 & 0.49 & 0.40 \\
\hline
\end{tabular}

Reactions:
(A) $5 \mathrm{C}_{4} \mathrm{H}_{6} \mathrm{O}_{4}+5 \mathrm{H}_{2}=4 \mathrm{C}_{5} \mathrm{H}_{8} \mathrm{O}_{4}+4 \mathrm{H}_{2} \mathrm{O}$;
(B) $6 \mathrm{C}_{4} \mathrm{H}_{6} \mathrm{O}_{4}+10 \mathrm{H}_{2}=4 \mathrm{C}_{6} \mathrm{H}_{10} \mathrm{O}_{4}+8 \mathrm{H}_{2} \mathrm{O}$;
(C) $4 \mathrm{C}_{5} \mathrm{H}_{8} \mathrm{O}_{4}+4 \mathrm{H}_{2} \mathrm{O}=5 \mathrm{C}_{4} \mathrm{H}_{6} \mathrm{O}_{4}+5 \mathrm{H}_{2}$;
(D) $6 \mathrm{C}_{5} \mathrm{H}_{8} \mathrm{O}_{4}+5 \mathrm{H}_{2}=5 \mathrm{C}_{6} \mathrm{H}_{10} \mathrm{O}_{4}+4 \mathrm{H}_{2} \mathrm{O}$;
(E) $4 \mathrm{C}_{6} \mathrm{H}_{10} \mathrm{O}_{4}+8 \mathrm{H}_{2} \mathrm{O}=6 \mathrm{C}_{4} \mathrm{H}_{6} \mathrm{O}_{4}+10 \mathrm{H}_{2}$;
(F) $5 \mathrm{C}_{6} \mathrm{H}_{10} \mathrm{O}_{4}+4 \mathrm{H}_{2} \mathrm{O}=6 \mathrm{C}_{5} \mathrm{H}_{8} \mathrm{O}_{4}+5 \mathrm{H}_{2}$.

twice. A first-order linear regression estimates the slope and intercept by minimizing the squared errors between the actual and predicted values of the dependent variable. In this exercise the slope is fixed by the reaction stoichiometry. Swapping the independent and dependent variables will invert the slope, producing a different intercept, a new value of $s^{2} / N$, and possibly a different $\log f_{\mathrm{H}_{2}}$ value.

The calculated $\log f_{\mathrm{H}_{2}}$ values agree within $0.3 \log$ units at $298.15 \mathrm{~K}$ with the maximum discrepancy increasing to $0.6 \log$ units at $473.15 \mathrm{~K}$. The water:rock ratio selected for calculation of dicarboxylic acid activity will affect the $\log a_{\mathrm{C} \gamma \mathrm{H}_{(2 \gamma-2)} \mathrm{O}_{4}}$-intercept value and thus the calculation of $\log f_{\mathrm{H}_{2}}$. Varying water:rock ratios by a factor of 100 results in only a limited variation (0.4 log units) of calculated $\log f_{\mathrm{H}_{2}}$ values (Figure 3 ).

\section{Discussion}

Do the $\log f_{\mathrm{H}_{2}}$ values calculated here accurately reflect the oxidation state of fluids during any stage of aqueous alteration? Because the paragenesis of dicarboxylic acid synthesis and alteration is unknown, interpretation of the $\log f_{\mathrm{H}_{2}}$ values calculated here is dependent on an interpretation of the thermal history of the carbonaceous chondrite parent body. Precise estimates of the temperature history during aqueous alteration are lacking. Measurements of the $\delta^{18} \mathrm{O}$ values of bulk phyllosilicates and carbonates from the Murchison meteorite have been interpreted as evidence that oxygen isotope exchange occurred at low temperatures (273.15-298.15 K) (Clayton and Mayeda, 1999). These measurements are difficult ones to make: the individual mineral grains are small and calcite and dolomite $\mathrm{CO}_{2}$ is recovered by sequential acidification of bulk samples (e.g. Benedix et al., 2003). Although the $\Delta^{17} \mathrm{O}$ values of Murchison carbonates and the water extracted from Murchison phyllosilicates are all similar $(\sim-0.8 \%$ ), the value reported for the Murchison matrix is much lower $(-1.8 \%$ o $)$ (Franchi et al., 2001). If the values for the Murchison matrix are representative of the phyllosilicate fraction then the phyllosilicate fraction did not form in isotopic equilibrium with either the carbonates or the phyllosilicate structural or interlayer water (Franchi et al., 2001). Baker et al. (2002) calculate an alteration temperature of $\sim 353 \mathrm{~K}$ using the $\delta^{18} \mathrm{O}$ values of the structural and interlayer water from phyllosil- icates and calcite from Murchison $\left(\Delta^{18} \mathrm{O}\right.$ calcite-water $=19 \%$ o). Measurements of the $\Delta_{47}$ anomaly (Ghosh et al., 2006) of three splits of Murchison carbonate yield alteration temperatures ranging from 293 to $306 \mathrm{~K}$, whereas temperatures up to $344 \mathrm{~K}$ are obtained from analyses of carbonate in the Cold Bokkevold meteorite (Guo and Eiler, 2007). Temperatures on asteroids have been interpreted to be 378-398 K (Hayatsu and Anders, 1981), with other workers suggesting that alteration occurred at temperatures as high as $403 \mathrm{~K}$ (Bunch and Chang, 1980) or $423 \mathrm{~K}$ (Zolensky et al., 1993). Modeling exercises have utilized temperatures ranging from 273.15 to $373.15 \mathrm{~K}$ (Cohen and Coker, 2000), 273.15 to $473.15 \mathrm{~K}$ (Schulte and Shock, 2004), and 274.15$423.15 \mathrm{~K}$ (Zolensky et al., 1989). Aqueous alteration on the Tagish Lake parent body was estimated to occur at temperatures <373.15 K (Zolensky et al., 2002).

We have attempted to relate the values of $\log f_{\mathrm{H}_{2}}$ calculated in this study using organic species to the inorganic chemistry of the meteorites using Figure 3. Figure 3 was drawn for a temperature range of 273.15-473.15 K. The hematite-magnetite (HM) and pyrite-pyrrhotite-magnetite (PPM) buffers are designated by the solid lines that begin at the right side of the diagram and terminate against the cronstedtite field on the left of the diagram. Cronstedtite is one of the more abundant alteration minerals in CM2 chondrites. It is stable at reducing conditions, low temperatures and activities of aqueous silica that approach quartz saturation (e.g. Figure 2 in Dyl et al., 2006). The three reactions that constrain cronstedtite stability on Figure 3 are

$$
\begin{aligned}
3 \mathrm{Fe}_{4} \mathrm{SiO}_{5}(\mathrm{OH})_{4(\text { cronstedtite) }}+16 \mathrm{FeS}_{2(\text { pyrite })}+15 \mathrm{H}_{2(\mathrm{~g})} \\
=32 \mathrm{Fe}_{0.875} \mathrm{~S}_{\text {(pyrrhotite) }}+3 \mathrm{SiO}_{2(\mathrm{aq})}+21 \mathrm{H}_{2} \mathrm{O} \\
3 \mathrm{Fe}_{4} \mathrm{SiO}_{5}(\mathrm{OH})_{4(\text { cronstedtite) }}=\mathrm{Fe}_{3} \mathrm{O}_{4 \text { (magnetite) }}+3 \mathrm{SiO}_{2(\mathrm{aq})} \\
+\mathrm{H}_{2(\mathrm{~g})}+5 \mathrm{H}_{2} \mathrm{O}
\end{aligned}
$$

and

$$
\begin{gathered}
\mathrm{Fe}_{4} \mathrm{SiO}_{5}(\mathrm{OH})_{4(\text { cronstedtite })}=2 \mathrm{Fe}_{2} \mathrm{O}_{3 \text { (hematite) }}+\mathrm{SiO}_{2(\mathrm{aq})} \\
+\mathrm{H}_{2(\mathrm{~g})}+\mathrm{H}_{2} \mathrm{O}
\end{gathered}
$$

Reactions (8), (9), and (10) have been plotted in $\log f_{\mathrm{H}_{2}}-T$ space (Figure 3 ) by fixing the activity of aqueous silica to $0.5 \log$ units below quartz saturation (the short dashed line), quartz saturation, and $0.5 \log$ units above (the long dashed line) quartz saturation. Although silica supersaturation will not occur under equilibrium conditions, amorphous silica is produced during computational modeling of the aqueous alteration of CM chondrites (Dyl et al., 2006). Moreover, short-term, high-temperature (up to $473.15 \mathrm{~K}$ ) aqueous alteration experiments using the Allende meteorite have produced amorphous, silica-rich phases (Jones and Brearley, 2006). Cronstedtite is typically stable only at low temperatures. Nucleation of cronstedtite at temperatures above $333 \mathrm{~K}$ requires kinetic inhibition of minnesotaite, a phase not typically reported in CM chondrites. The reaction path calculation of Schulte and Shock (2004) does not produce cronstedtite above $\sim 323 \mathrm{~K}$ but cronstedtite-bearing alteration mineral assemblages are preserved at temperatures up to $373 \mathrm{~K}$. 


\begin{tabular}{lllllll}
\multicolumn{6}{l}{ Table 4. $\log f_{\mathrm{H}_{2}}$ values calculated based on water/ rock $=1 / 1$} \\
\hline$T(\mathrm{~K})$ & \multicolumn{1}{l}{$\log f_{\mathrm{H}_{2}}$ values calculated from reactions A-F } \\
\cline { 2 - 7 } & $\mathrm{A}$ & $\mathrm{B}$ & $\mathrm{C}$ & $\mathrm{D}$ & $\mathrm{E}$ & $\mathrm{F}$ \\
\hline 298.15 & -6.3 & -6.2 & -6.3 & -6.0 & -6.2 & -6.0 \\
348.15 & -4.3 & -4.1 & -4.3 & -3.9 & -4.1 & -3.9 \\
373.15 & -3.5 & -3.3 & -3.5 & -3.1 & -3.3 & -3.1 \\
423.15 & -2.2 & -2.0 & -2.2 & -1.7 & -2.0 & -1.7 \\
473.15 & -1.3 & -1.0 & -1.3 & -0.7 & -1.0 & -0.7 \\
\hline
\end{tabular}

Reactions:

(A) $5 \mathrm{C}_{4} \mathrm{H}_{6} \mathrm{O}_{4}+5 \mathrm{H}_{2}=4 \mathrm{C}_{5} \mathrm{H}_{8} \mathrm{O}_{4}+4 \mathrm{H}_{2} \mathrm{O}$;

(B) $6 \mathrm{C}_{4} \mathrm{H}_{6} \mathrm{O}_{4}+10 \mathrm{H}_{2}=4 \mathrm{C}_{6} \mathrm{H}_{10} \mathrm{O}_{4}+8 \mathrm{H}_{2} \mathrm{O}$;

(C) $4 \mathrm{C}_{5} \mathrm{H}_{8} \mathrm{O}_{4}+4 \mathrm{H}_{2} \mathrm{O}=5 \mathrm{C}_{4} \mathrm{H}_{6} \mathrm{O}_{4}+5 \mathrm{H}_{2}$;

(D) $6 \mathrm{C}_{5} \mathrm{H}_{8} \mathrm{O}_{4}+5 \mathrm{H}_{2}=5 \mathrm{C}_{6} \mathrm{H}_{10} \mathrm{O}_{4}+4 \mathrm{H}_{2} \mathrm{O}$;

(E) $4 \mathrm{C}_{6} \mathrm{H}_{10} \mathrm{O}_{4}+8 \mathrm{H}_{2} \mathrm{O}=6 \mathrm{C}_{4} \mathrm{H}_{6} \mathrm{O}_{4}+10 \mathrm{H}_{2}$;

(F) $5 \mathrm{C}_{6} \mathrm{H}_{10} \mathrm{O}_{4}+4 \mathrm{H}_{2} \mathrm{O}=6 \mathrm{C}_{5} \mathrm{H}_{8} \mathrm{O}_{4}+5 \mathrm{H}_{2}$.

The $\log f_{\mathrm{H}_{2}}$ values calculated in this study are consistent with those estimated based on previous mineralogical examinations of carbonaceous chondrites (e.g. Zolensky et al., 1993) but cover a narrower range of $\log f_{\mathrm{H}_{2}}-T$ space. The curves calculated from this study (Figure 3 ) are the average values of $\log f_{\mathrm{H}_{2}}$ as a function of temperature for the six reactions examined in Table 4 calculated for three different values of water:rock ratio. The Schulte and Shock (2004) path in Figure 3 is the $\log f_{\mathrm{H}_{2}}-T$ path for their coupled mineral alteration/organic synthesis simulation from 273.15 to $473.15 \mathrm{~K}$. If the path developed in the Schulte and Shock (2004) simulation is an accurate approximation of the prograde alteration on the parent body, then the values of $\log f_{\mathrm{H}_{2}}$ calculated in this study may record a later, retrograde, more oxidizing, period of aqueous alteration. The values of $\log f_{\mathrm{H}_{2}}$ calculated here are, however, generally consistent with the mineralogy of the Murchison and Y-791118 meteorites. The dicarboxylic acid species could therefore have reached metastable equilibrium at temperatures approaching $353 \mathrm{~K}$ in contact with cronstedtite + magnetite and in an aqueous solution in which the activity of aqueous silica approached quartz saturation (Figure 3). The maximum temperature range of equilibrium with cronstedtite ranges from 300 to $355 \mathrm{~K}$ if a water:rock ratio of 10:1 and quartz saturation are assumed.

The values calculated in this study are more oxidizing than those presented in a recent examination of the $\delta^{13} \mathrm{C}$ and $\delta^{18} \mathrm{O}$ values of carbonates from the Murchison, Murray and Cold Bokkevold meteorites. Guo and Eiler (2007) interpreted a negative correlation between the carbonate $\delta^{13} \mathrm{C}$ values and the calculated $\delta^{18} \mathrm{O}$ values for the alteration water as evidence for reduction of aqueous carbonate to methane during alteration with subsequent loss of the methane. Guo and Eiler (2007) obtained an Eh value of $-0.67 \mathrm{~V}\left(\log f_{\mathrm{H}_{2}}=-2.6\right)$ and a $\mathrm{pH}$ value of 12.5 by modeling a fluid in equilibrium with a $\mathrm{CM}$ chondrite alteration assemblage at $301 \mathrm{~K}$. Methane loss can occur under conditions slightly more oxidizing than those defined by the trace of the $\mathrm{CH}_{4(\mathrm{aq})}-\mathrm{HCO}_{3}^{-}{ }_{(\mathrm{aq})}-\mathrm{CO}_{3}^{2-}$ (aq) triple point (Figure 3) depending on total dissolved carbon, fluid salinity, and pressure. Again, if the values obtained in this study are accurate, then they must reflect a later, more oxidizing period of alteration. Methane loss could have been a significant mechanism for fluid oxidation if the loss of methane was rapid relative to heterogeneous equilibrium.

Progressively more oxidizing conditions during aqueous alteration are indicated by the presence of calcite and sulfate veins proximal to more reduced mineral assemblages (Kerridge and Bunch, 1979). Although the $\Delta^{17} \mathrm{O}$ values of sulfate from CM2 chondrites deviate from the terrestrial fractionation line, the values obtained from Murchison sulfate do not match the $\Delta^{17} \mathrm{O}$ values of the phyllosilicate matrix, phyllosilicate structural or interlayer water, or carbonates (cf. [Baker et al., 2002; Airieau et al., 2005). Nor are the distribution of dicarboxylic acid species consistent with metastable equilibrium during a sulfide oxidizing event. The $\log f_{\mathrm{H}_{2}}$ values of the $\mathrm{H}_{2} \mathrm{~S}_{(\mathrm{aq})}-\mathrm{SO}_{4}^{2-}$ (aq) $-\mathrm{HS}^{-}{ }_{\text {(aq) }}$ triple point are plotted in Figure 3 for reference. The dicarboxylic acid species could only reach metastable equilibrium with a sulfate fluid at temperatures approaching $273.15 \mathrm{~K}$.

It must be noted that specific ratios in the abundances of organic species, interpreted as evidence of metastable equilibrium (Shock, 1988; Shock, 1989; Shock, 1990), may originate from other processes. One example is the generation of monocarboxylic acids during the thermal maturation of kerogen (Bell and Palmer, 1994). Extending this argument to the carbonaceous chondrite samples, the soluble cyclic compounds in Murchison have been suggested to originate from macromolecular material (Sephton et al., 1998). Pyrolysis of the Yamato-791198 carbonaceous chondrite yielded an array of heterocyclic compounds, saturated alkanes of 9-14 carbon atoms, propanenitrile, and dimethylsulfide from the macromolecular material (Komiya et al., 1993). Carboxylic acids, however, were not identified and evidence for the synthesis of carboxylic acids during pyrolysis of chondrite macromolecular organic material is lacking.

\section{Conclusions}

The concentrations of C4-C9 saturated dicarboxylic acids in carbonaceous chondrite samples are correlated in a way that suggests that the acids were in metastable equilibrium during aqueous alteration on the meteorite parent body. Because the slopes of these relations are fixed by the stoichiometry of the reactions relating the species of interest, the oxidation state can be retrieved. The linearity of the plots based on samples of different carbonaceous chondrites suggests similar thermal and redox histories among the CM2 carbonaceous chondrites sampled and that the Murchison and Y-791118 meteorites were derived from the same parent body. Calculation of $\log f_{\mathrm{H}_{2}}$ values as a function of temperatures is possible by minimizing the variance on the plots on which the slope is fixed by the stoichiometry of the reaction indicating metastable equilibrium. Based on metastable equilibrium among succinic (C4), glutaric (C5), and adipic (C6) acids and a water:rock ratio of 1:1 during aqueous alteration, values of $\log f_{\mathrm{H}_{2}}$ calculated range from -6.2 at $298 \mathrm{~K}$ to -3.3 at $373 \mathrm{~K}$. The values of $\log f_{\mathrm{H}_{2}}$ calculated are consistent with those proposed for hydrothermal alteration of carbonaceous chon- 
drites based on petrographic studies but more oxidizing than values proposed for methane-producing systems. The results obtained here support the application of metastable equilibrium to problems of organic synthesis in aqueous systems.

\section{Acknowledgments}

This work comprises a portion of the senior author's Masters Thesis at the University of Nebraska-Lincoln. We acknowledge Dr. Donald A. Palmer, Dr. T. D. Frank and Dr. D. B. Loope for review of that manuscript and for providing helpful comments. We thank Dr. A. N. Krot and two anonymous reviewers for Geochimica et Cosmochimica Acta for their reviews of this manuscript as well as Dr. S. Pizzarello and two anonymous reviewers for their reviews of an earlier version of this manuscript. Discussions with Dr. D. K. Watkins regarding data reduction were helpful. We thank Dr. Weifu Guo for providing a copy of their manuscript prior to publication. Errors of interpretation or fact are our sole responsibility. Financial support was provided by NSF EAR 0230323 and a University of Nebraska Department of Geosciences Alumni Fellowship.

\section{References}

Airieau et al., $2005<$ S. A. Airieau, J. Farquhar, M. H. Thiemens, L. A. Leshin, H. Bao, and E. Young, Planetesimal sulfate and aqueous alteration in CM and CI carbonaceous chondrites, Geochim. Cosmochim. Acta 69 (2005), pp. 4167-4172.

Anders et al., 1973 E. Anders, R. Hayatsu, and M. Studier, Organic compounds in meteorites, Science 182 (1973), pp. 781-790.

Apelblat and Manzurola, 1987 A. Apelblat and E. Manzurola, Solubility of oxalic, malonic, succinic, adipic, maleic, citric, and tartaric acids in water from 278. 15 to 338. 15 K, J. Chem. Thermodyn. 19 (1987), pp. 317-320.

Baker et al., 2002 L. Baker, I. A. Franchi, I. P. Wright, and C. T. Pillinger, The oxygen isotopic composition of water from Tagish Lake; its relationship to low-temperature phases and to other carbonaceous chondrites, Meteorit. Planet Sci. 37 (2002), pp. 977-985.

Barber, 1985 D. J. Barber, Phyllosilicates and other layerstructured materials in stony meteorites, Clay Miner. 20 (1985), pp. 415-454.

Bell and Palmer, 1994 J. L. S. Bell and D. A. Palmer, Experimental studies of organic acid decomposition. In: E. D. Pittman and M. D. Lewan, Editors, Organic Acids in Geological Processes, Springer-Verlag, Berlin, Germany (1994), pp. 226-269.

Benedix et al., 2003 G. K. Benedix, L. A. Leshin, J. Farquhar, T. Jackson, and M. H. Thiemens, Carbonates in CM2 chondrites; constraints on alteration conditions from oxygen isotopic compositions and petrographic observations, Geochim. Cosmochim. Acta 67 (2003), pp. 1577-1588.

Botta and Bada, 20024 O. Botta and J. L. Bada, Extraterrestrial organic compounds in meteorites, Surv. Geophys. 23 (2002), pp. 411-467.

Brandon et al., $2005<$ A. D. Brandon, M. Humayun, I. S. Puchtel, and M. E. Zolensky, Re-Os isotopic systematics and platinum group element composition of the Tagish Lake carbonaceous chondrites, Geochim. Cosmochim. Acta 69 (2005), pp. 1619-1631.

Brearley, 2006 A. J. Brearley, The action of water. In: D. S. Lauretta and H. Y. McSween Jr., Editors, Meteorites and the Early Solar System II, The University of Arizona Press, USA (2006), pp. 587-624.

Bunch and Chang, $1980<$ T. E. Bunch and S. Chang, Carbonaceous chondrites. II. Carbonaceous chondrite phyllosilicates and light element geochemistry as indicators of parent body processes and surface conditions, Geochim. Cosmochim. Acta 44 (1980), pp. 1543-1577.

Carothers and Kharaka, 1978 W. W. Carothers and Y. K. Kharaka, Aliphatic acid anions in oil-field waters-implications for origin of natural gas, Am. Assoc. Petrol. Geol. Bull. 62 (1978), pp. 2441-2453.

Chyba and Sagan, $1992 \varangle$ C. Chyba and C. Sagan, Endogenous production, exogenous delivery and impact-shock synthesis of organic molecules: an inventory for the origins of life, Nature 335 (1992), pp. 125-132.

Clayton and Mayeda, $1999<$ R. N. Clayton and T. K. Mayeda, Oxygen isotope studies of carbonaceous chondrites, Geochim. Cosmochim. Acta 63 (1999), pp. 2089-2104.

Cohen and Coker, $2000 \varangle$ B. A. Cohen and R. F. Coker, Modeling of liquid water on CM meteorite bodies and implications for amino acid racemization, Icarus 145 (2000), pp. 369-381.

Cronin et al., 1993 J. R. Cronin, S. Pizzarello, R. V. Krishnamurthy, and S. Epstein, Molecular and isotope analyses of the hydroxyl acids, dicarboxylic acids, and hydroxydicarboxylic acids of the Murchison meteorite, Geochim. Cosmochim. Acta 57 (1993), pp. 4745-4752.

Dyl et al., 2006 K. A. Dyl, C. E. Manning, and E. D. Young, Modeling aqueous alteration of CM carbonaceous chondrites; implications for cronstedtite formation by waterrock reaction. Lunar Planet. Sci. XXXVII, Lunar Planet. Inst., Houston, \#2060 (2006) (abstr).

Franchi et al., 2001 I. A. Franchi, L. Baker, J. C. Bridges, I. P. Wright, and C. T. Pillinger, Oxygen isotopes and the early Solar System, Philos. Trans. Roy. Soc. A 359 (2001), pp. 2019-2035.

Ghosh et al., 20064 P. Ghosh, J. Adkins, H. Affek, B. Balta, W. Guo, E. A. Schauble, D. Schrag, and J. M. Eiler, ${ }^{13} \mathrm{C}-{ }^{18} \mathrm{O}$ bonds in carbonate minerals: a new kind of paleothermometer, Geochim. Cosmochim. Acta 70 (2006), pp. 1439-1456.

Guo and Eiler, 2007 W. Guo and J. M. Eiler, Temperatures of aqueous alteration and evidence for methane generation on the parent bodies of the CM chondrites, Geochim. Cosmochim. Acta 71 (2007); doi 10. 1016/j. gca. 2007. 07. 029.

Hayatsu and Anders, 1981 Hayatsu R., and Anders E. (1981) Organic compounds in meteorites and their origins. In Cosmo-and Geochemistry, Vol. 99: Topics in Current Chemistry, Springer-Verlag, Berlin, Germany, pp. 1-37.

Helgeson et al., $1993<$ H. C. Helgeson, A. M. Knox, C. E. Owens, and E. L. Shock, Petroleum, oil field waters, and authigenic mineral assemblages: are they in metastable equilibrium in hydrocarbon reservoirs?, Geochim. Cosmochim. Acta 57 (1993), pp. 3295-3339.

Jones and Brearley, $2006 \varangle$ C. L. Jones and A. J. Brearley, Experimental aqueous alteration of the Allende meteorite under oxidizing conditions: constraints on asteroidal alteration, Geochim. Cosmochim. Acta 70 (2006), pp. 1040-1058. 
Kerridge, 19914 J. F. Kerridge, A note on the prebiotic synthesis of organic acids in carbonaceous meteorites, Origin Life Evol. Biosph. 21 (1991), pp. 19-29.

Kerridge and Bunch, 1979 J. F. Kerridge and T. E. Bunch, Aqueous activity on asteroids: evidence from carbonaceous meteorites. In: T. Gehrels, Editor, Asteroids, University of Arizona Press, Tucson, USA (1979), pp. 745-764.

Komiya et al., $1993 \varangle$ M. Komiya, A. Shimoyama, and K. Harada, Examination of organic compounds from insoluble organic matter isolated from some Antarctic carbonaceous chondrites by heating experiments, Geochim. Cosmochim. Acta 57 (1993), pp. 907-914.

Krot et al., 20034 A. N. Krot, K. Keil, C. A. Goodrich, E. R. D. Scott, and M. K. Weisberg, Meteorite classification. In: A. M. Davis, H. D. Holland and K. K. Turekian, Editors, Meteorites, Comets, and Planets, Elsevier, Boston, USA (2003), pp. 83-128.

Krot et al., 2006 A. N. Krot, I. D. Hutcheon, A. J. Brearley, O. V. Pravdivtseva, M. I. Petaev, and C. M. Hohenberg, Timescales and settings for alteration of chondritic meteorites. In: D. S. Lauretta and H. Y. McSween Jr., Editors, Meteorites and the Early Solar System II, The University of Arizona Press, USA (2006), pp. 587-624.

Maiella and Brill, $1996 \varangle$ P. G. Maiella and T. B. Brill, Spectroscopy of hydrothermal reactions. 5. Decarboxylation kinetics of malonic acid and monosodium malonate, J. Phys. Chem. 100 (1996), pp. 14352-14355.

Martins et al., 2006 Z. Martins, J. S. Watson, M. A. Sephton, O. Botta, P. Ehrenfreund, and I. Gilmour, Free dicarboxylic and aromatic acids in the carbonaceous chondrites Murchison and Orguiel, Meteorit. Planet. Sci. 41 (2006), pp. 1073-1080.

McCollom and Seewald, $2003 \triangleleft$ T. M. McCollom and J. S. Seewald, Experimental constraints on the hydrothermal reactivity of organic acids and acid anions. I. Formic acid and formate, Geochim. Cosmochim. Acta 67 (2003), pp. 3625-3644.

Peltzer, 1979 Peltzer, E. T. 1979. Geochemistry of hydroxy and dicarboxylic acids. Ph. D. Thesis, University of California, San Diego.

Peltzer et al., 1984 E. T. Peltzer, J. L. Bada, G. Schlesinger, and S. L. Miller, The chemical conditions on the parent body of the Murchison meteorite: some conclusion based on amino, hydroxyl and dicarboxylic acids, Adv. Space Res. 4 (1984), pp. 69-74.

Pizzarello and Huang, 2002 S. Pizzarello and Y. Huang, Molecular and isotopic analyses of Tagish Lake alkyl dicarboxylic acids, Meteorit. Planet. Sci. 37 (2002), pp. 687-696.

Pizzarello et al., 2006 S. Pizzarello, G. W. Cooper, and G. J. Flynn, The nature and distribution of the organic material in carbonaceous chondrites and interplanetary dust particles. In: D. S. Lauretta and H. Y. McSween Jr., Editors, Meteorites and the Early Solar System II, The University of Arizona Press, USA (2006), pp. 587-624.
Schulte and Shock, $2004 \varangle$ M. Schulte and E. Shock, Coupled organic synthesis and mineral alteration on meteorite parent bodies, Meteorit. Planet. Sci. 39 (2004), pp. 1577-1590.

Seewald, $1994<$ J. S. Seewald, Evidence for metastable equilibrium between hydrocarbons under hydrothermal conditions, Nature 370 (1994), pp. 285-287.

Seidell, 1941 A. Seidell, Solubilities of Organic Compounds, Van Nostrand, New York (1941).

Sephton, 20024 M. A. Sephton, Organic compounds in carbonaceous meteorites, Nat. Product Rep. 19 (2002), pp. 292-311.

Sephton et al., 19984 M. A. Sephton, C. T. Pillinger, and I. Gilmour, ${ }^{13} \mathrm{C}$ of free and macromolecular aromatic structures in the Murchison meteorite, Geochim. Cosmochim. Acta 62 (1998), pp. 1821-1828.

Shimoyama and Shigematsu, 1994 A. Shimoyama and R. Shigematsu, Dicarboxylic acids in the Murchison and Yamato-791198 carbonaceous chondrites, Chem. Lett. (1994), pp. 523-526.

Shock, 19884 E. L. Shock, Organic acid metastability in sedimentary basins, Geology 16 (1988), pp. 886-890.

Shock, 19894 E. L. Shock, Corrections to "Organic acid metastability in sedimentary basins," Geology 17 (1989), pp. 572-573.

Shock, 1990 E. L. Shock, Geochemical constraints on the origin of organic compounds in hydrothermal systems, Origin Life Evol. Biosph. 20 (1990), pp. 331-367.

Weber, 20044 A. L. Weber, Kinetics of organic transformations under mild aqueous conditions: Implications for the origin of life and its metabolism, Origin Life Evol. Biosph. 34 (2004), pp. 473-495.

Willey et al., 19754 L. M. Willey, T. K. Kharaka, T. S. Presser, J. B. Rapp and I. Barnes, Short chain aliphatic acid anions in oil field waters and their contribution to the measured alkalinity, Geochim. Cosmochim. Acta 39 (1975), pp. 1707-1711.

Yezdimer et al., $2000<$ E. M. Yezdimer, J. Sedlbauer, and R. H. Wood, Predictions of thermodynamic properties at infinite dilution of aqueous species at high temperatures via functional group additivity, Chem. Geol. 164 (2000), pp. $259-280$

Zolensky et al., $19894 \mathrm{M}$. Zolensky, W. L. Bourcie,r and J. L. Gooding, Aqueous alteration on the hydrous asteroids: results of EQ3/6 computer simulations, Icarus 78 (1989), pp. 411-425.

Zolensky et al., $1993<\mathrm{M}$. Zolensky, R. Barrett, and L. Browning, Mineralogy and composition of matrix and chondrule rims in carbonaceous chondrites, Geochim. Cosmochim. Acta 57 (1993), pp. 3123-3148.

Zolensky et al., 2002 M. E. Zolensky, K. Nakamura, M. Gounelle, T. Mikouchi, T. Kasama, O. Tachikawa, and E. Tonui, Mineralogy of Tagish Lake: an ungrouped type 2 carbonaceous chondrite, Meteorit. Planet. Sci. 37 (2002), pp. 737-761. 